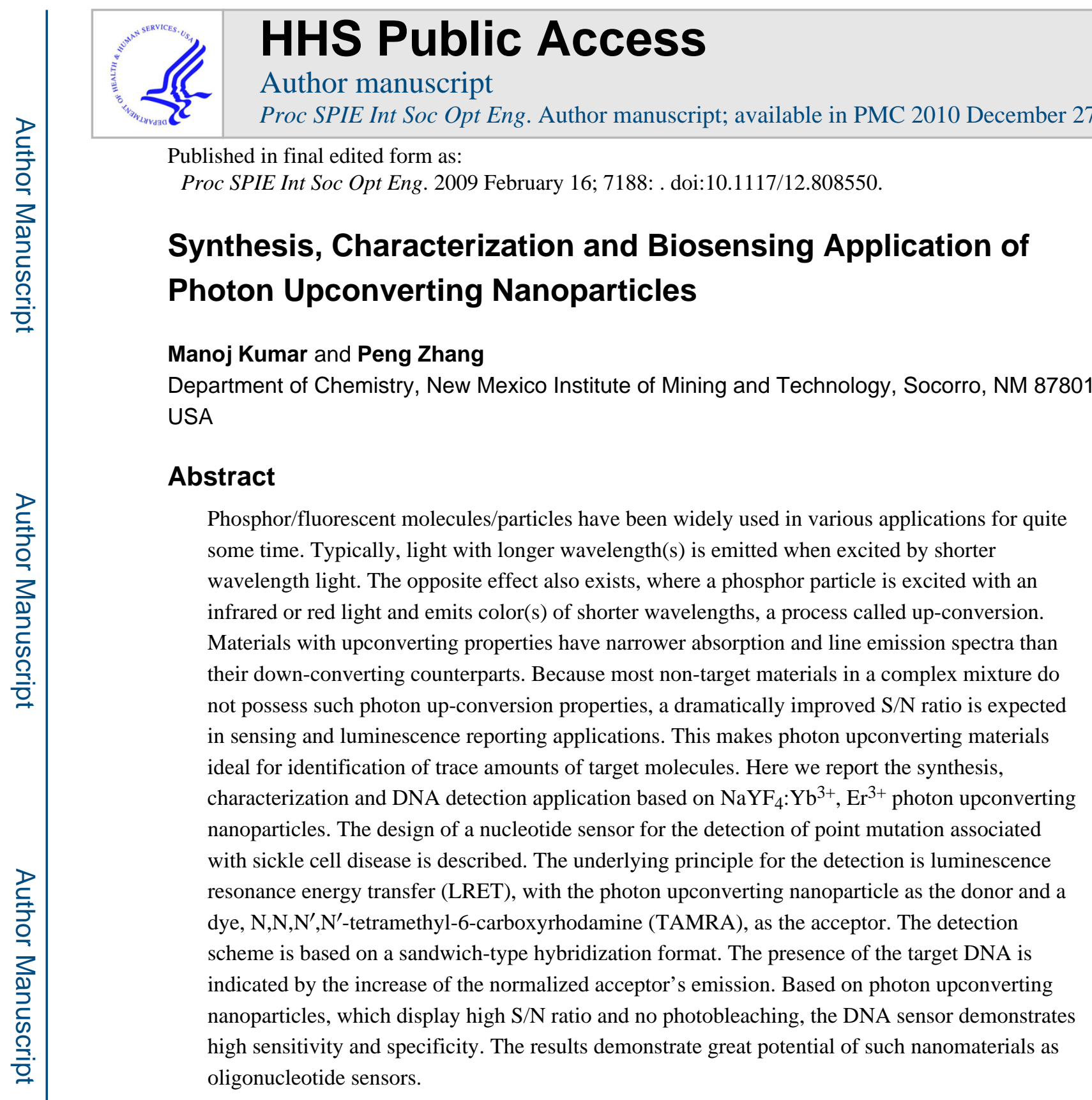

\title{
Keyword list
}

Photon upconversion; DNA detection; Energy transfer; Nanoparticles

\section{Introduction}

Advances in the field of optics has lead to wide acceptance of optical based biosensors, due to their ability to do remote sensing, highly non-invasive for in vivo studies and to provide high selectivity and sensitivity.[1] Biosensors relying on photonic interaction with analytes for detection require some kind of fluorescent/luminescent labeling. For many years organic fluorophores have been used as conventional fluorescent tags. These dyes follow stokes law and absorb one high-energy photon and emit one low-energy photon. These dyes in solution exhibit broad emission and excitation bands and tend to show compromised photo stability at prolonged exposure to intense excitation sources. Use of such dyes in the design of 
biosensors has played very crucial role in the development of optical biosensors.

Nevertheless, there has been constant desire in the research community to seek for higher selectivity and sensitivity for the designed sensors. In an effort to achieve higher selectivity and sensitivity, use of intense excitation source, low noise from background, strong signals from the dyes becomes highly desirable feature for biosensing.

In contrast to organic dyes there exists a type of materials, which follow anti-stokes law and absorb two or more low-energy photons and emit one high energy photon.[2] These materials are known as photon upconverting materials. These materials absorb in near infra red (NIR) region, are highly photostable, exhibit narrow emission and excitation bands.

Thus photon upconverting materials demonstrate outstanding prospects for use in biosensing as well as in imaging-based application as luminescent tags. There have been many materials exhibiting upconversion properties, although photon upconverting materials based on $\mathrm{NaYF}_{4}: \mathrm{Yb}^{3+}, \mathrm{Er}^{3+}$ or $\mathrm{NaYF}_{4}: \mathrm{Yb}^{3+}, \mathrm{Tm}^{3+}$ demonstrate higher luminescent property due to low phonon- photon coupling. The emission bands of the upconverting materials depend upon the choice of the acceptor ions. These upconverting materials find extensive use in display technologies, probable use in sensing applications, imaging and many others.

In recent years many researchers have demonstrated the efficient use of photon upconverting particles in biosensing.[3-6] Application of photon upconverting particles in imaging and sensing has drawn considerable interest of researcher towards the synthesis and characterization of such nanoparticles. Synthesis of nanoparticles with or without scaffolding of $5-50 \mathrm{~nm}$ range without compromising the quantum yield and their subsequent use in bio-related application is highly desirable. In this proceeding, we present our ongoing efforts in the direction of synthesis and characterization of photon upconverting particles such as $\mathrm{NaYF}_{4}: \mathrm{Yb}^{3+}, \mathrm{Er}^{3+}$, along with their subsequent use in DNA sensing applications.

\section{Experimental}

\section{Chemicals}

All chemicals were used as bought without further purification. $\mathrm{NaF}, \mathrm{YbCl}_{3} \cdot 6 \mathrm{H} 2 \mathrm{O}, \mathrm{YCl}_{3}$. $6 \mathrm{H}_{2} \mathrm{O}$, potassium phosphate mono basic $\left(\mathrm{K}_{2} \mathrm{HPO}_{4}\right)$ and potassium phosphate dibasic $\left(\mathrm{KH}_{2} \mathrm{PO}_{4}\right)$, ethylene-bis(oxyethylenenitrilo) tetraaceticacid (EGTA), ethylenediaminetetraaceticacid (EDTA), tetraethyl orthosilicate (TEOS) were purchased from Sigma Aldrich, where as cyanogens bromide (CNBr) was purchased from Fisher Scientific. Phosphate buffer of require $\mathrm{pH}$ and concentrations were prepared by mixing $\mathrm{KH}_{2} \mathrm{PO}_{4}$ and $\mathrm{K}_{2} \mathrm{HPO}_{4}$ in calculated amounts. All DNA sequences used were purchased from Integrated DNA Technologies (Coralville, IA).

\section{Synthesis of photon upconverting $\mathrm{NaYF}_{4}: \mathrm{Yb}^{3+}, \mathrm{Er}^{3+}$ nanoparticles}

Photon upconverting particles were synthesized in laboratory using wet chemistry route. The synthesis route was a modification over previous method described elsewhere.[7] Here we tend to briefly present the synthesis procedure followed. $3.2 \mathrm{ml}$ of $\mathrm{YCl}_{3}, 0.68 \mathrm{ml}$ of $\mathrm{YbCl}_{3}$, $0.12 \mathrm{ml} \mathrm{ErCl}_{3}$, mixed together with $4 \mathrm{ml}$ of EGTA of $0.2 \mathrm{M}$ concentration in a clean glass vial. This mixture was stirred overnight and then $12 \mathrm{ml}$ of $0.83 \mathrm{M} \mathrm{NaF}$ was added to the 
stated mixture, allowed to react for 2 hours at $130^{\circ} \mathrm{C}$ in autoclave, and then nanoparticles were separated from the solution by centrifuging at $14000 \mathrm{rpm}$. The synthesized nanoparticles were washed with acetone and then with DI water several times to wash out organic matter. After several washing synthesized nanoparticles were annealed at $325^{\circ} \mathrm{C}$ for 3 hours.

\section{TEM characterization of $\mathrm{NaYF}_{4}: \mathrm{Yb}^{3+}, \mathrm{Er}^{3+}$ nanoparticles}

Synthesized nanoparticles were dispersed in methanol and sonicated thoroughly using BRANSON Sonifier. A drop of the suspension was deposited on a copper-grid covered with carbon-coated Formavar film (Electron Microscopy Sciences, PA). Samples were analyzed using JOEL TEM.

\section{Luminescence characterization of $\mathrm{NaYF}_{4}: \mathrm{Yb}^{3+}, \mathrm{Er}^{3+}$ nanoparticles}

Synthesized nanoparticles after annealing at $325^{\circ} \mathrm{C}$ were suspended in $100 \mathrm{mM}$ phosphate buffer ( $\mathrm{pH} 7.0$ ) by rigorous stirring. The suspension was excited at $975 \mathrm{~nm}$, using a diode laser (CrystaLaser, NV) at $~ 300 \mathrm{~mW}$. Emission slit was fixed at 2nm and PMT was operated at $1 \mathrm{kV}$.

\section{Silica coating}

The synthesized nanoparticles $\left(\mathrm{NaYF}_{4}: \mathrm{Yb}^{3+}, \mathrm{Er}^{3+}\right)$ were coated with a thin silica layer to allow further attachment of recognition elements. The procedures for coating were a variation of the well-known Stöber reaction.[8] In brief, the synthesized nanoparticles were suspended in $80 \mathrm{ml}$ of 2-propanol by sonicating thoroughly. To the suspension $8.94 \mathrm{ml}$ of $28 \%$ ammonium hydroxide, $7.5 \mathrm{ml}$ of DI water and $0.1 \mathrm{ml}$ of TEOS were added. To ensure uniform coating, mixture was allowed to stir continuously for 24 hours and then, coated nanoparticles were separated by centrifuging at $14000 \mathrm{rpm}$. The separated nanoparticles were thoroughly washed with methanol and DI water and collected as thick slurry for later use.

\section{Oligonucleotide sequences}

Four Oligonucleotide sequences based on desired detection scheme were ordered. These sequences were 13, 11, 26 and 26 bases long, respectively, as listed in Table 1. Various targets ordered were based on the segments of the human hemoglobin beta chain (HBB). The 13-base long oligo target, labeled as DNA_probe, was modified at its fifth prime end with amine, for attachment of DNA with silica-coated photon upconverting nanoparticles. DNA_Mis is a mutant form of HBB, available at NIH's NCBI gene bank as (AY356351).[9]

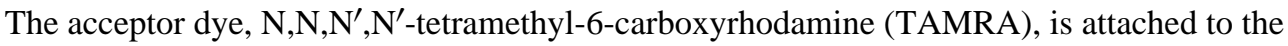
11-base long oligonucleotide (DNA_Fl).

\section{Attachment of DNA to silica coating}

The amine modified DNA was attached to the silica modified nanoparticles. The following protocol was based on $100 \mathrm{mg}$ of silica coated nanoparticles. Silica coated particles were weighed and washed twice in $10 \mathrm{ml}$ phosphate buffer of $\mathrm{pH} 8.0$, with $1 \mathrm{mM}$ EDTA. After washing the nanoparticles were separated and re-suspended in the $9.5 \mathrm{ml}$ of sodium 
carbonate buffer of $2 \mathrm{M}$ concentration. To the suspension $1 \mathrm{mg}$ of cyanogen bromide dissolved in $0.5 \mathrm{ml}$ of acetonitrile was added and allowed to stir for 2 minutes. Activated nanoparticles were separated out by centrifuging at $14000 \mathrm{rpm}$ and then washed several times with ice cold phosphate buffer ( $\mathrm{pH}$ 8.0) followed by DI water. Then these particles were re-suspended in $5 \mathrm{ml}$ of phosphate buffer ( $\mathrm{pH} 8.0$ ) to which $\sim 420 \mu \mathrm{L}$ of $50 \mu \mathrm{M}$ DNA_probe was added. Conjugation reaction was allowed to carry out at $4{ }^{\circ} \mathrm{C}$ for 24 hours. After 24 hours reaction mixture was quenched with large amount of phosphate buffer of $\mathrm{pH}$ 7.0. DNA-conjugated nanoparticles were separated and washed several times with the phosphate buffer of $\mathrm{pH} 7.0$ and then re-suspended in $\sim 600 \mu \mathrm{L}$ phosphate buffer of $\mathrm{pH} 7.0$ for later use.

\section{Assay measurements}

Assay measurements were carried out using spectrofluorometer (Photon Technologies International) equipped with R928 photon multiplier tube from Hamamatsu. To one of the side ports, diode laser of $\sim 975 \mathrm{~nm}$ and $\sim 1 \mathrm{~W}$ power was externally attached.

Spectrofluorometer was also attached with a water bath (NESLAB, RTE-10) to maintain the sample temperature. PMT was operated at $1.1 \mathrm{KV}$, with laser output of $400 \mathrm{~mW}$, slit width of $2 \mathrm{~nm}$ and cuvette temperature at $22{ }^{\circ} \mathrm{C}$, for all the measurements.

$70 \mu \mathrm{L}$ of DNA-conjugated nanoparticles suspension and $60 \mu \mathrm{L}$ of $1 \mu \mathrm{M}$ DNA_Fl were mixed together as blank, and three spectra were acquired. To the blank, $1 \mu \mathrm{M}$ of DNA_Tar or $4 \mu \mathrm{M}$ of DNA_Mis was added with increment of $2.5 \mu \mathrm{L}$. Data were acquired 25 minutes after each addition to allow for hybridization. Hybridization reaction was carried out in phosphate buffer of $\mathrm{pH} 7$ and $100 \mathrm{mM}$ concentration.

\section{Results and discussion}

\section{TEM characterization of photon upconverting nanoparticles}

Synthesized nanoparticles after annealing were characterized for the size distribution. The micrograph acquired (Figure 1) for the nanoparticles show the size distribution of nanoparticles ranging from $50 \mathrm{~nm}$ to $100 \mathrm{~nm}$. The size of the synthesized nanoparticles was determined to be $72 \mathrm{~nm}$ on randomly taking average of 50 nanoparticles.

\section{Luminescent characterization of photon upconverting nanoparticles}

The synthesized photon upconverting nanoparticles exhibit little luminescence before annealing. After annealing at $325^{\circ} \mathrm{C}$ for four hours, they display intense luminescence upon excitation at $\sim 975 \mathrm{~nm}$, shown in Figure 2. These bands in visible region corresponds corresponding to ${ }^{4} \mathrm{~S}_{3 / 2} \rightarrow{ }^{4} \mathrm{I}_{13 / 2},{ }^{4} \mathrm{~F}_{9 / 2} \rightarrow{ }^{4} \mathrm{I}_{15 / 2},{ }^{2} \mathrm{~S}_{3 / 2} \rightarrow{ }^{4} \mathrm{I}_{15 / 2}$, and ${ }^{2} \mathrm{H}_{11 / 2} \rightarrow{ }^{4} \mathrm{I}_{15 / 2}$ electronic transitions. The energies associated with these electronic transitions are approximately $11800,15000,18200$ and $18800 \mathrm{~cm}^{-1}$ respectively, as reported in the literature.[10]

\section{Scheme of the detection}

The detection scheme was based on Luminescent Resonance Transfer (LRET) in a sandwich format, where two short oligonucleotides capture one long target (Figure 3). One of the short 
probes was attached to the nanoparticles; whereas the other short oligonucleotide was labeled with TAMRA. Photon upconverting particles served as energy donor whereas TAMRA acted as energy acceptor. The donor-acceptor pair was chosen based on the spectral overlap from the emission of nanoparticles ( $525 \mathrm{~nm}$ to $550 \mathrm{~nm})$ with the excitation band of TAMRA $(\sim 550 \mathrm{~nm})$. The dye absorbed emission at $550 \mathrm{~nm}$ and emitted at $575 \mathrm{~nm}$. When DNA-conjugated nanoparticles and DNA_Fl were added as a blank, there was little energy transfer between the two. Upon addition of perfectly matched target, DNA duplexes between DNA_Probe, DNA_Fl and DNA_Tar were formed, leading to LRET between the donor and the acceptor. Thus increase in the emission from the TAMRA accompanied with subsequent increase in concentration of target DNA concentration would indicate any hybridization occurred.

\section{Sensitivity of the detection}

The sensitivity of the detection was calculated based on the detection of the matched target. Upon hybridization of probe and target lead to increase in the emission of dye, normalized with respect to the emission from the donor nanoparticles. Such ratiometric detection schemes not only account for any disturbance inherent to the measuring and surrounding environment but also increase the dynamic range of the detection.[3,11] Signal $f$ was calculated as the percentage increase in the emission of the dye, mathematically given as

$$
f=\left[\left(I_{575} / I_{537}\right)-\left(I_{575} / I_{537}\right)_{\text {blank }}\right] /\left(I_{575} / I_{537}\right)_{\text {blank }}
$$

This calculated $f$ value was plotted against the increase in concentration of the target in the blank due to subsequent additions. Based on $\mathrm{S} / \mathrm{N}=3$ ratio, first five points of the perfectly matched targets were used to determine the detection limit, as $0.65 \mathrm{nM}$. The detection limit reported was found comparable to or better than many other reported schemes.

\section{Selectivity of the detection scheme}

In order to critically asses the selectivity capability of the sensor, DNA_Mis, a single nucleotide variant (sickle cell anemia, point mutation gene portion), was chosen, presented in the Table 1. The point mutation is flanked by two guanines, which provides higher stability to annealing or to destabilizing duplex and hence offering challenge to any kind of superior sensors. In bioanalytical analysis success of sensor critically depends on its ability to distinguish desired targets from matrix element present in very high concentration compared to desired target. Thus in order to test the superiority of the senor, DNA_Mis was taken in $4 \times$ greater concentration to the perfectly matched target. The signal $f$ plotted for DNA_Tar and DNA_Mis against concentration yields a linear response of slope which is 7.5 times more sensitive for the perfectly matched target than for the mismatch target.

\section{Conclusion}

DNA probe of our design has demonstrated the ability to clearly distinguish perfectly matched target from the single nucleotide variant at four time higher concentration as compared to matched targets. The proposed design of DNA probe based on photon 
upconverting nanoparticles is full of promise for high selective and sensitive oligonucleotide detection. These nanoparticles probably can be used for detecting genes responsible for cancer, without further amplification and transcription of RNA into DNA.

\section{Acknowledgments}

This work was partially supported by Grant Number RR-016480 from the National Center for Research Resources (NCRR) of the National Institutes of Health (NIH).

\section{References}

1. Prasad, PN. Introduction to Biophotonics. Wiley Interscience; NJ: 2003.

2. Auzel FE. Chem Rev. 2004; 104:139. [PubMed: 14719973]

3. Zhang P, Rogelj S, Nguyen K, Wheeler D. J Am Chem Soc. 2006; 128:12410. [PubMed: 16984179]

4. Kuningas K, Ukonaho T, Päkkilä H, Rantanen T, Rosenberg J, Lövgren T, Soukka T. Anal Chem. 2006; 78:4690. [PubMed: 16808483]

5. Kuningas K, Päkkilä H, Ukonaho T, Rantanen T, Lövgren T, Soukka T. Clinical Chem. 2007; 53:145. [PubMed: 17202501]

6. Kumar M, Guo Y, Zhang P. Biosens Bioelectron. 200810.1016/j.bios.2008.08.023

7. Yi G, Lu H, Zhao S, Ge Y, Yang W, Chen D, Guo L. Nano Lett. 2004; 4(11):2191.

8. Santra S, Zhang P, Wang K, Tapec R, Tan W. Anal Chem. 2001; 73(20):4988. [PubMed: 11681477]

9. National Center for Biotechnology Information (NCBI). www.ncbi.nlm.nih.gov/entrez/viewer.fcgi? $\mathrm{db}=$ nuccore $\& \mathrm{id}=34224020$

10. Suyver JF, Aebischer A, Biner D, Gerner P, Grimm J, Heer S, Kramer KW, Reinhard C, Gudel HU. Opt Mater. 2005; 27:1111.

11. Zhang P, Tan W, Beck T. Angew Chem Int Ed. 2001; 40(2):402. 


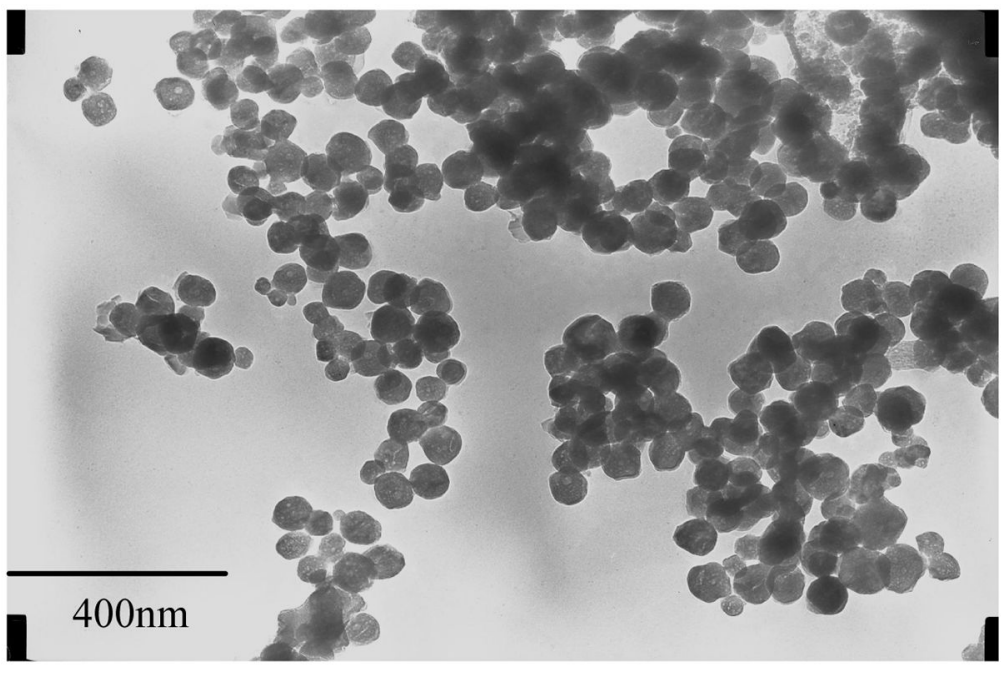

Figure 1.

TEM micrograph of photon upconverting particles after annealing 


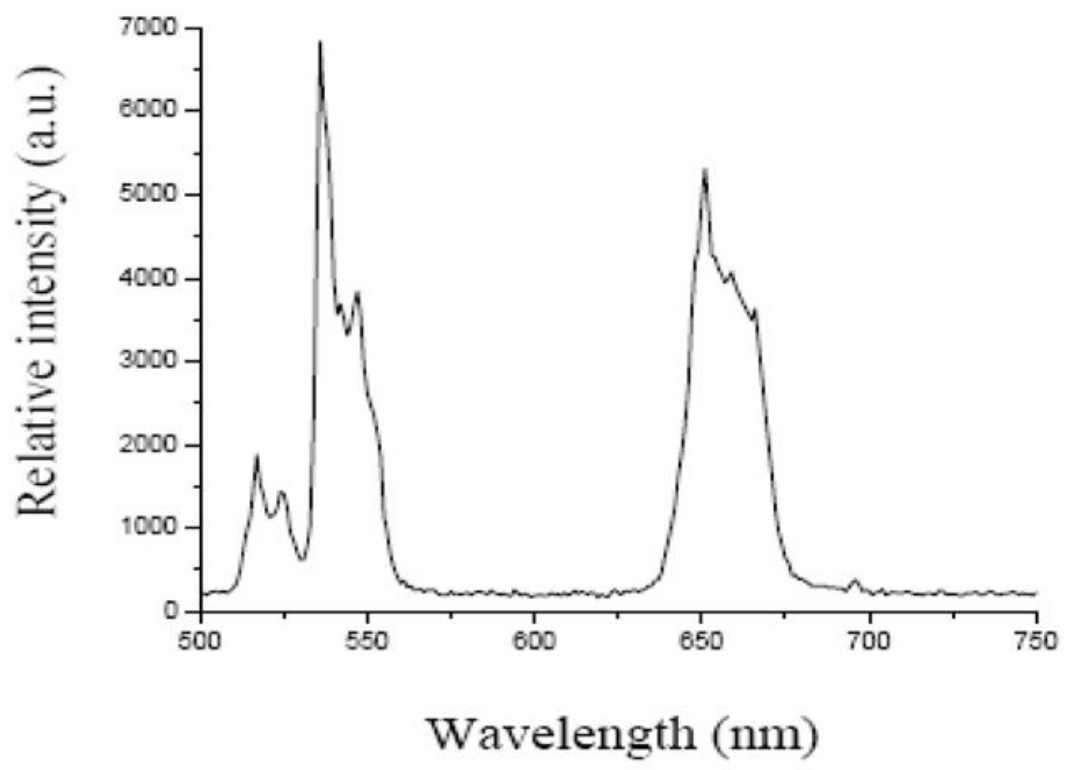

Figure 2.

Luminescent spectra of photon upconverting nanoparticles after annealing, suspended in phosphate buffer of $\mathrm{pH} 7$ of $100 \mathrm{mM}$ concentration and 1mM EDTA. 


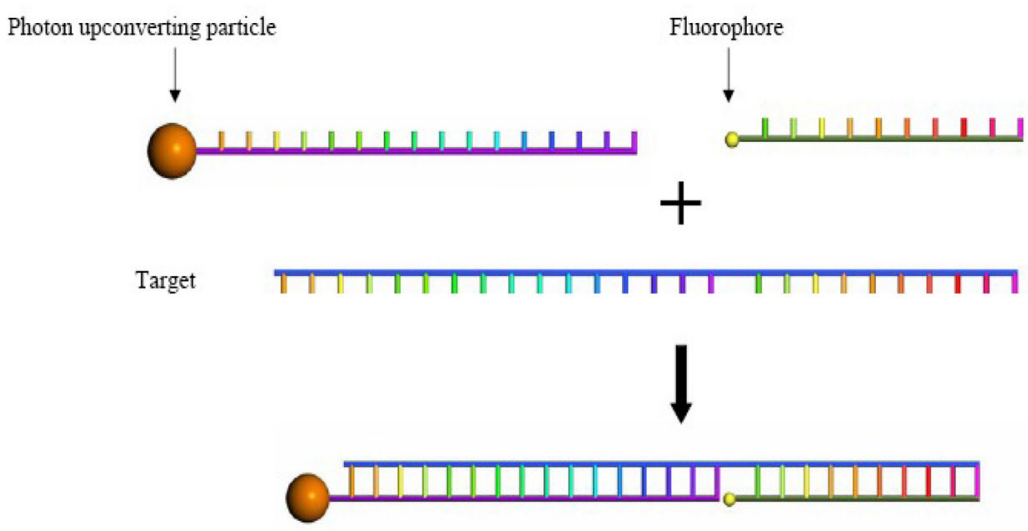

Figure 3.

Sandwich format for detecting DNA Targets 


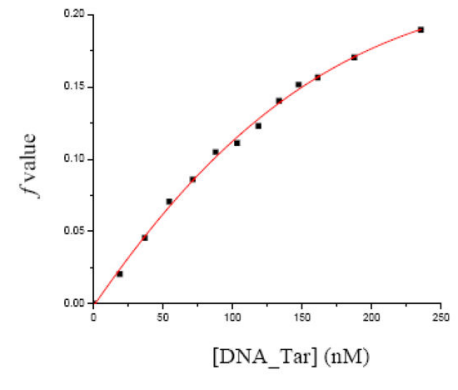

(a)

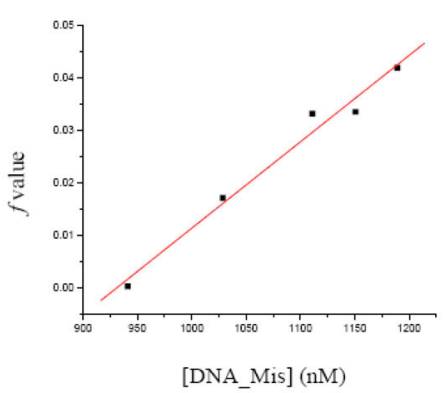

(b)

Figure 4.

Plot of $f$ value vs.: (a) [DNA_Tar] and (b) [DNA_Mis], upon excitation of photon upconverting particles at $975 \mathrm{~nm}$. 
Table 1

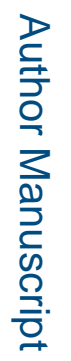

\begin{tabular}{|l|l|l|}
\hline Oligonucleotide & Sequence & No. of bases \\
\hline DNA_Probe & 5'-/AmineC $_{6}$ /CAGTAACGGCAGA-3' & 13 \\
\hline DNA_Fl & 5'-/TAMRA/TCTCCACAGGA-3' $^{\prime}$ & 11 \\
\hline DNA_Tar & 5'-TCCTGTGGAGAAGTCTGCCGTTACTG-3' $^{\prime}$ & 26 \\
\hline DNA_Mis & 5'-TCCTGAGGGGAAGTCTGCCGTTACTG-3' $^{\prime}$ & 26 \\
\hline
\end{tabular}

